\title{
Iconografía de Polifemo: el Cíclope enamorado
}

\author{
María Isabel RODRÍGUEZ LÓPEZ \\ Universidad Complutense de Madrid
}

Recibido: 27-2-2013 / Aceptado: 27-6-2013

RESUMEN: Presentamos con este trabajo un recorrido a través de la iconografía de Polifemo basada en los textos de Teócrito y Ovidio, desde la Antigüedad hasta el Simbolismo. El rústico cíclope, enamorado de Galatea, hace música para la nereida mientras goza de su imagen o se duele en la melancolía. La presencia de otro pastor, Acis, suscita los celos del Cíclope, proporcionando a los artistas de todos los tiempos una historia muy sugerente, plagada de no pocas connotaciones plásticas y simbólicas. En ella se armonizan los contrarios: el mar, el fuego, la tierra, la música, el viento... el amor y la voluptuosidad frente a las fuerzas oscuras y brutales.

Palabras clave: Polifemo, Galatea, Iconografía Clásica, Mitología Clásica, Tradición clásica en el arte.

ABSTRACT: We present this work in order to trace a journey through the iconography of Polyphemus based on the texts of Theocritus and Ovid, from Antiquity to Symbolism. The rustic Cyclop, in love with Galatea, creates music for the nereid while he is enjoying her image or is hurting in melancholy. The presence of another shepherd Acis, arouses the jealousy of the Cyclop, which gives artists of all times a very inspiring story, full of quite a few visual and symbolic connotations. In this, the opposites are harmonized: the Sea, Fire, Earth, Music, Wind ... Love and Voluptuousness against the dark and brutal forces.

Key Words: Polyphemus, Galatea, Classic Iconography, Classic Mythology, Classic tradition in Art.

«Nada más triste que un titán que llora, hombre-montaña encadenado a un lirio, que gime, fuerte, que pujante implora: víctima propia de su fatal martirio...»

(Rubén Darío)

\section{EL MITO DE POLIFEMO COMO PASTOR ENAMORADO.}

Según los mitógrafos, Polifemo es hijo del dios marino Posidón y la ninfa Toosa (hija ésta de Forcis), un ser de estirpe marina. Pertenece a la familia de los Cíclopes sicilianos, y como ellos es un ser brutal y gigantes$\mathrm{co}$, de prodigiosa fuerza y extraño aspecto, con un solo ojo sobre su frente ${ }^{1}$. Su protagonismo en el canto IX de la Odisea, donde se

\footnotetext{
${ }^{1}$ El nombre del cíclope es $K \dot{v} \kappa \lambda \omega \psi,-\pi o \varsigma$. Su etimología es un compuesto sobre la raíz de círculo, circular, redondo, (kykl-) у o廿, oтós, ojo. Significa, de ojo redondo. En Teogonía 144, Hesíodo dice: Cíclopes era su nombre por eponimia, ya que, efectivamente, un solo ojo completamente redondo se hallaba en su frente.
} 
relata el encuentro con Ulises y sus compañeros ${ }^{2}$, hace de Polifemo el más popular entre sus semejantes. Homero lo describe como el más salvaje de todos los Cíclopes, ajeno a la hospitalidad y devorador de hombres ${ }^{3}$, un pastor brutal que no conoce el cultivo de la vid y que, según nos cuenta Homero, come carne cruda y posee instintos antropófagos:

"Dando un salto, sus manos echó sobre dos de mis hombres, los cogió cual si fueran cachorros, les dio contra el suelo y corrieron vertidos los sesos mojando la tierra. En pedazos cortando sus cuerpos dispuso la cena: devoraba, al igual del león que ha crecido en los montes, sin dejarse ni entrañas ni carnes ni huesos meolludos. (...)"

Eurípides se refiere, asimismo, a la antropofagia del brutal Polifemo:

"De tu ancha garganta, oh Cíclope, abre de par en par el labio, puesto que, cocidos, asados y fuera de las brasas, dispuestos están para ti los miembros de tus huéspedes, para que los roas, mastiques y desgarres, reclinado en tu espesa piel de cabra!(...)"

Y esa brutalidad caníbal del hijo de Posidón la expresan, también otros autores, entre los que destaca Ovidio con sus Metamorfosis:

"Me invade un pálido horror al contemplar su rostro aún empapado por la carnicería, y sus manos crueles y la vacía órbita de su ojo y sus miembros y su barba apelmazada por la sangre humana (...)"6.

¿Cómo el imaginario griego pudo transformar a este ser feroz en un enamorado?; ¿y cómo los mitógrafos pudieron

\footnotetext{
${ }^{2}$ Odisea, IX, 181-566.

${ }^{3}$ RODRÍGUEZ LÓPEZ, M. I., “Iconografía de Polifemo en la tradición homérica y sus pervivencias" CFG (G) Estudios griegos e indoeuropeos 2010, 20, pp. 177-198.

${ }^{4}$ Odisea IX, 288-293.

${ }^{5}$ El Cíclope, 357-360.

${ }^{6}$ Metamorfosis XIV, 198-201.
}

convertir a este monstruo en un músico? La concepción bestial del Cíclope formada en los textos homéricos, deja, en efecto, poca cabida a los afectos humanos o a la vocación musical de un ser entretenido únicamente en sus brutales costumbres y alejado de la civilización. Sin embargo, este Polifemo homérico, un pastor que cuida de sus rebaños y vive en una caverna comiendo carne cruda, posee ciertas afinidades con los sátiros, por lo que, andando el tiempo, poetas y artistas habrían de adjudicarle algunos atributos dionisíacos, entre ellos el uso de la siringa (acaso una metáfora del viento), que pasaría a ser uno de sus distintivos más comunes. Como los sátiros, Polifemo utiliza también el cayado de pastor, cubre su desnudez con pieles de animales para señalar su salvajis$\mathrm{mo}^{7}$ y dormita el sueño beodo; es un espíritu salvaje, expresiva encarnación personificada de un lugar dominado por la potencia violenta de la Naturaleza.

Por otra parte, no olvidemos que Polifemo es un hijo del mar y que con él viven sus rumores y sus sonidos; es también un ser que habita en los páramos rocosos de un volcán rugiente (el Etna). No resulta extraño, en nuestra opinión, que tanto escritores como artistas plásticos terminaran por asociar su figura con el sonido -aullido o sollozo- del viento, o con el bufido que causa el mar bravío al batir con las rocas donde el gigante moraba.

Los textos de la tradición bucólica del Helenismo hicieron de Polifemo un enamorado ${ }^{8}$. El brutal pastor pasaría entonces a ser el protagonista de una aventura amorosa, gozada -y sufrida- con Galatea, una nereida

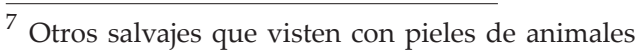
como atributo iconográfico son los Gigantes. Cf. RODRÍGUEZ LÓPEZ, M.I., "El asalto al Olimpo: la Gigantomaquia", De Arte. Revista de Historia del Arte. Universidad de León, n.8, 2009, pp.7-26.

${ }^{8}$ Un interesante estudio del Cíclope enamorado puede seguirse en GARCÍA LÓPEZ, Y., "The subordination of the epic to mystic poetics: the example of Polyphemus in love", en: M. DÍAZ DE CERIO, C. Cabrillana (eds.), Studies in ancient epic (en prensa).
} 
que habitaba en el calmo mar de Sicilia y cuyo nombre evoca la blancura de la leche ${ }^{9}$. La primera alusión literaria a los amores de Polifemo y Galatea se sitúa en torno al año 400 a.C., cuando Filóxeno de Citera (345-380 a.C.), un poeta cortesano de Siracusa, compuso un novedoso ditirambo titulado El Cíclope o Galatea, obra en la que se presenta al feroz Polifemo consolándose de su mal de amores mediante el canto, acompañado del son de la lira. La obra, de la que apenas se conservan unos pocos fragmentos, debió de recrear una leyenda popular siciliana que revivía la relación amorosa entre la pareja ${ }^{10}$. Tras la obra de Filóxeno, varios escritores siguieron su senda y se inspiraron en dichos amores ${ }^{11}$, dando lugar a una nueva tradición literaria, la bucólica, bien distante de la visión homérica ${ }^{12}$.

Fue Teócrito el definitivo responsable de esta visión galante del Cíclope como ser tierno y no exento de cierta coquetería ${ }^{13}$. Las inclinaciones musicales de Polifemo, no sugeridas directamente por Homero y la tradición homérica, pasan en esta visión pastoril a primer plano, dado que la música formaba parte esencial en la usanza de la literatura bucólica, siempre referida a escenarios naturales y protagonizada por sencillos

\footnotetext{
${ }^{9}$ La nereida Galatea es la personificación de la blancura del mar que asoma a las costas sicilianas, un mar en calma cuya superficie produce brillantes destellos bajo el sol que se tornan blanquecinos. No en vano, el mar mediterráneo fue designado por los turcos como el "mar blanco", el Akh Deniz. Cf. "Bahr" en Encyclopédie de L'Islam, París (1913-1942).

${ }^{10}$ Cf. SANCHO ROJO, A., "Análisis de los motivos de composición del Cíclope de Filóxeno de Cítera", $\mathrm{Ha}$ bis n.14 (1983), pp. 33-50.

11 En realidad había sido Eurípides en su Cíclope (vv. 582 y ss.), quien había mostrado con anterioridad la vertiente amatoria de Polifemo, aunque el trágico sacara a la luz una versión del amor pederástico que Polifemo, cuando se hallaba embriagado, sentía por Sileno.

12 Merecen citarse Nicócares, Antífanes, Timoteo, Cratino, Epicarmo, o Nicandro. Cf. SANCHO ROJO, Op. Cit. , p. 34.

13 BRIOSO SÁNCHEZ, M., Bucólicos griegos, Madrid, Akal, 1986.
}

pastores embelesados por albas ninfas. Esta poesía refleja también la calma de la Naturaleza, cuyos espíritus, masculino y femenino, se funden en armoniosa unidad.

Como veremos, Polifemo canta su amor no correspondido, o se duele en el silencio melancólico ante el desamor de su amada, observándola -sin apenas apartar de ella su mirada-. En ocasiones sus instintos atroces resurgen, especialmente cuando los celos desatan su furia. $Y$ así lo imaginaron los pintores desde la Roma altoimperial, en los frescos pompeyanos, los ciclos pictóricos que sirvieron de ornato a las grandes residencias principescas de la Edad Moderna, los artistas galantes, neoclásicos, románticos y muy en particular, los simbolistas modernos ${ }^{14}$.

Una tradición relata que su amor fue correspondido y que Galatea le dio tres hijos (éponimos de los pueblos gálatas, celtas e ilirios), pero no nos ha llegado ningún testimonio literario directo de tales requiebros: " $Y$ cuentan que el país tomó el nombre a partir de Ilirio, el hijo de Polifemo, pues el Cíclope Polifemo y Galatea tuvieron tres hijos: Celto Ilirio y Gala, que emigraron desde Sicilia y gobernaron sobre los celtas ilirios y Gálatas, llamados así por su causa"15.

En el Idilio VI, Teócrito evoca cómo la nereida suele rechazar los requerimientos amorosos del Cíclope, aunque ocasionalmente coquetea con él, desencadenando su vanidad:

Al fin y al cabo, no soy tan feo como dicen, que el otro día, cuando había bonanza, miréme en el mar, y mi barba y mi única pupila, a mi juicio, lucían hermosas, y el agua reflejaba el brillo de mis dientes más blanco que el mármol de Paros $(. . .)^{16}$.

El Idilio XI consta de 81 versos, la mayoría de los cuales (19-79) forman la canción con

\footnotetext{
${ }^{14}$ Cf. ELVIRA BARBA, M.A., Arte y mito en la Antigua Grecia, Manual de Iconografía clásica, Madrid, 2008, p.140.

${ }^{15}$ Apiano, Ilir. 2.

${ }^{16}$ Teócrito, Idilio VI, 34-38.
} 
la que Polifemo trata de ganarse el favor de su amada:

"Fomentaba su amor y su esperanza

Polifemo cantando; y más contento pasaba allí la vida placentera que si montones de oro poseyera"(...)

"De ti me enamoré, doncella mía, en cuanto aquí llegaste con mi madre para coger jacintos en el monte, y era yo vuestro guía.

Después de haberte visto, ni antes pude dejar de amarte, ni puedo ahora, no, desde aquel día.

Pero a ti nada te importa, por Zeus, nada (...)". "¿Por qué, cándida ninfa Galatea,

del que rendido te ama huyes esquiva?

Tu pura tez cual requesón blanquea, y más que un ternerillo eres altiva; cual uva que inmadura verdeguea amarga, y que un cordero más festiva, llegas si al dulce sueño cierro el ojo, y al despertar, de huir te viene antojo?» 17

Ovidio imaginó la presencia de un tercer personaje, el pastor Acis (hijo de Pan), creando con él un triángulo amoroso. Los amoríos del joven y bello pastor con la nereida provocaron los celos del salvaje en quien resurgía la naturaleza monstruosa. Cuenta Ovidio que estando un día Galatea reposando sobre el pecho de su amado, al borde del mar, fue sorprendida por Polifemo, que trató de aniquilar a su rival, lanzándole una enorme piedra. Aplastado el pastor, su cuerpo fue metamorfoseado en un río de cristalino caudal que muere (o desemboca) en el mar habitado por la blanca ninfa:

"¿Por qué, tras rechazar al Cíclope, amas a Acis y prefieres a Acis a mis abrazos? [...] Arrancaré sus vísceras vivas y esparciré sus miembros y pedazos por los campos y por tus aguas (ique así se mezcle contigo!). Pues me abraso y el fuego herido hierve más cruelmente, y me parece que llevo en mi pecho al Etna trasladado con sus fuerzas: iy tú Galatea no te conmueves! [Habla Galatea]: Le sigue

\footnotetext{
17 Teócrito, Idilio XI.
}

el Cíclope y le arroja un trozo arrancado de un monte $y$, aunque sólo le alcanzó un trozo extremo de la roca, sin embargo enterró por completo a Acis. [...] Sangre color púrpura manaba de la mole y al poco tiempo empezó a desvanecerse el color rojo, se convierte primero en el color de un río enturbiado por la lluvia que se aclara con el tiempo; después la mole se resquebraja $y$ se fractura, y por las grietas surge una caña verde y espigada y la boca hueca de la roca suena con el brote de las aguas: $y$ hecho admirable, de pronto sobresalió hasta medio cuerpo un joven con cuernos nuevos ceñidos con flexibles cañas, quien, si no fuera porque era mayor y porque era azul en toda su cara, era Acis. Pero así y todo era Acis convertido en río, y el río conservó su antiguo nombre (...)". ${ }^{18}$

\section{DESARROLLO ICONOGRÁFICO EN LA ANTIGUA ROMA.}

Los ciclos pictóricos de la Antigüedad se encargaron de recrear esta aventura mitológica, que tuvo gran aceptación entre la sociedad romana durante en los años iniciales del imperio, unida a la moda de la literatura bucólica; este asunto pasó a ser motivo recurrente en la decoración de las residencias de las elites romanas, tanto en Roma como en la bahía de Nápoles. El cíclope y la nereida celebran su idilio en las pinturas, donde la iconografía muestra diferentes episodios:

1. -la conversación entre Polifemo y Galatea

2. -la carta que Galatea escribe a Polifemo

3. -la llegada de la nereida

4. -la consumación del amor (concebida como abrazo sensual y erótico)

Comenzaremos refiriéndonos a un conocido fresco procedente de la Villa de Boscotrecase (Metropolitan Museum, Nueva

\footnotetext{
18 Ovidio, Metamorfosis XIII, 740-897.
} 
York) ${ }^{19}$. Esta pintura, obra maestra entre las de su género, decoró la pared oriental de alcoba 19, el llamado "Cuarto Mitológico", en la Villa imperial de Boscotrecase. Pertenece al sistema decorativo pompeyano conocido como "Tercer estilo", procedimiento en el que las escenas mitológicas de diversa naturaleza fueron predilectas para decorar las habitaciones de las casas romanas.

La pintura pone ante nuestros ojos una imagen sinóptica, que combina dos momentos separados de la vida del cíclope: su aventura amorosa con Galatea y el encuentro con Odiseo. Ambos episodios se funden en un paisaje bucólico al servicio de la Mitología; de tal suerte que los personajes se disponen sobre un fondo al aire libre, en el que los efectos perspectivos y la gama cromática utilizada han sido meticulosamente estudiados. Como es bien sabido, los paisajes bucólicos y/o mitológicos tienen en común una fórmula compositiva caracterizada por la presencia de una columna o elemento vertical en el centro. Entre sus rasgos más frecuentes merecen señalarse también la dilatada perspectiva que sugiere misteriosas lejanías y la relación entre el primer plano y las escenas de fondo, así como la atmósfera que envuelve las escenas y las integra en su aire. En primer plano, Polifemo está sentado en el centro de la composición, sobre un afloramiento rocoso, cuidando de sus cabras. Sostiene en su mano derecha su flauta, una siringa de múltiples cañas ${ }^{20}$, y mira fijamente a la hermosa Galatea que aparece montada sobre un delfín, en el margen izquierdo del cuadro, sobre la superficie marina. En la parte superior del conjunto puede adver-

\footnotetext{
${ }^{19}$ La Villa de Boscotrecase ha sido objeto de numerosos estudios, de entre los que destacamos: ANDERSON, D., MAXWELL, L. "Pompeiian Frescoes in The Metropolitan Museum of Art", MMA Bulletin 45. New York: Metropolitan Museum of Art, 1987. BLANCKENHAGEN, P. H. von, ALEXANDER, Ch.. The Paintings from Boscotrecase. Heidelberg: F. H. Kerle, 1962.

${ }^{20}$ La siringa es un instrumento unido, ya desde la civilización griega (syrinx polikalamós), a la tradición pastoril. Su práctica está fuera de la civilización y de la instrucción musical.
}

tirse la faceta más brutal del cíclope, lanzando una piedra al fugado Odiseo cuya nave se divisa en la lontananza, surcando el mar (Fig. 1).

El Polifemo pintado en la casa de Livia, en el Palatino, hoy conservado sólo por dibujos, es una creación muy original, que no comparte características compositivas ni formales con otros ejemplos conocidos. El único aspecto en común con la pintura de Boscotrecase es la identidad de los protagonistas. En este caso, el Cíclope está sumergido en el mar, del que emerge su busto, observando a la ninfa. Un erote, situado sobre sus hombros alude a su condición de enamorado, que en esta ocasión no se representa mediante la música.

El idilio adquiere otra dimensión en algunas obras en las que se representa el amor correspondido. Así, por ejemplo, un fresco de la Casa del Naviglio o di Zefiro e Flora [Pompeya, VI, 10, 11], realizado según los parámetros del llamado IV estilo pompeyano (45-79 d.C.), hoy en el Museo Arqueológico de Nápoles, muestra a Polifemo en el preciso momento de recibir una carta de Galatea. Sentado en un risco, el enamorado cíclope alarga su mano para asir el mensaje que le entrega un pequeño erote montado a lomos de un delfín. Con gran maestría, el artista ha desplazado el punto central de la composición hacia la izquierda, hasta el vacío existente entre las manos de los dos personajes, que tratan de unirse; se subraya, de este modo, la importancia de la pequeña misiva en la que reside la suerte del amante.

La fisonomía de este Polifemo está bastante humanizada y sólo una leve mancha sobre su frente alude a su condición ciclópea. Por lo demás, su anatomía muestra a un hombre en la plenitud física, que cubre sus piernas con una piel de animal (atributo que indica su condición marginal y salvaje) y sostiene con su mano izquierda una lira de cinco cuerdas y caja de resonancia formada por un caparazón de tortuga. También es visible un pequeño plectro. El instrumento de cuerda 
no es habitual en las representaciones canónicas de Polifemo, habitualmente acompañado de la siringa ${ }^{21}$. Creemos que ocasión la presencia de esta rústica lira contribuye, también, a resaltar la delicadeza y la "humanización" del personaje, un enamorado que canta versos para su amada, acompañándose con la dulce sonoridad del cordófono, de acuerdo con el citado texto de Filóxeno de Citera ${ }^{22}$. Sin embargo, llama la atención la morfología de la lira, de acabado tosco, como conviene a un instrumento fabricado por un pastor. Sobre las rocas, un áspero cayado de cabrero completa la caracterización iconográfica de Polifemo (Fig. 2).

Análogo carácter "humano" se vislumbra en otra pintura de la Casa de Meleagro (obra del llamado IV estilo pompeyano) en la que dos figuras femeninas se acercan a Polifemo. Creemos que una de ellas, la situada en último término, es la sirvienta que advierte al cíclope de la presencia de su señora, situada en primer término, frente a Polifemo. Sentado en la roca, con el cayado en la mano y cubierto parcialmente por una piel de pantera, el cíclope gira su cabeza ante la noticia, haciendo un gesto elocuente con su mano derecha, entre sorprendido y turbado. Vuelve su cuerpo para contemplar a la ninfa, que hace ademán de abanicarse delicadamente y cuya blanca piel destaca en el conjunto ${ }^{23}$. En esta ocasión, no hay lugar para la presencia de instrumento musical alguno y la caracterización de

\footnotetext{
${ }^{21}$ Entre las innovaciones introducidas por Filóxeno de Citera en el ditirambo se cuenta el acompañamiento con lira en un género aulódico. Sabemos por las fuentes clásicas que Filóxeno, Timoteo y Celestes llevaron a cabo una renovación musical del ditirambo, rompiendo con la tradición previa. Entre sus innovaciones se cuentan la ausencia de responsión estrófica, los cambios de compases y tono, la alternancia de diferentes modos musicales, la introducción de la lira y el uso de variadísimos artificios literarios puestos al servicio de la música. Cf. SANCHO ROJO, A., Op. Cit., p. 46.

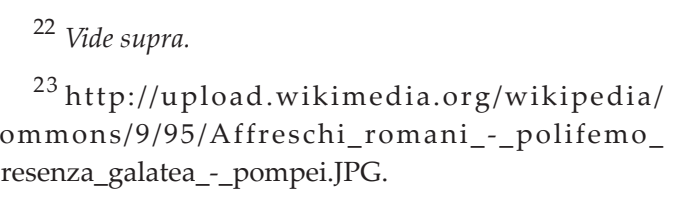

Polifemo se completa únicamente con el cayado de remate curvilíneo, el pedum, asociado tantas veces a su efigie. La interpretación romana del mito resulta de todo punto excepcional, ya que descubre la presencia de Galatea como una dama romana de buena posición, ataviada con decoro y acompañada de su sirvienta. Mito y realidad se entremezclan en estas obras, concebidas con sentido eminentemente decorativo para deleitar, de modo fútil, a sus propietarios. Estas pinturas no debieron tener intención simbólica alguna más que la de amenizar con una historia extravagante y conocida y así rememorar los versos de Teócrito, y Ovidio, tan de moda en la Roma altoimperial.

El amor entre la ninfa marina y el cíclope se consuma excepcionalmente. Un pequeño fresco de Pompeya, procedente de la Casa della Caccia Antica ${ }^{24}$ representa un abrazo sensual, de tono casi erótico, entre los protagonistas. La carnación bruna de Polifemo, se contrapone con la blancura de la ninfa, vista de espaldas y representada como una joven de formas mórbidas y voluptuosas. La identidad de los personajes se expresa con la presencia, a la izquierda, de un ariete, de la siringa y del pedum, además de una cabra situada en primer plano. Las figuras se destacan sobre un fondo neutro y están ejecutadas a base de pinceladas rápidas y ligeras, muy adecuadas para otorgar delicadeza al conjunto pictórico. El asunto tiene la particularidad de mostrar un lado poco usual del mito, ya que habitualmente Galatea no consiente de forma tan explícita al cortejo de Polifemo. En este caso, la siringa reposa en el suelo, callada, pero su presencia es alusión al agasajo previo al momento representado. Se trata de un instrumento en forma de ala que tiene unidas sus cañas por una agarradera; el grosor del instrumento sugiere, que pudiera tener doble hilera de tubos (Fig.3).

Las composiciones pictóricas conocidas fueron emuladas, como es sabido,

\footnotetext{
$\overline{{ }^{24} \text { Pompeya Regio VII, 4, 48, ambiente } 15}$.
} 
por otras realizadas con técnica musivaria. Entre dichas manifestaciones destacamos un mosaico pavimental procedente de la antigua Corduba conservado hoy en el Alcázar de los Reyes Cristianos de Córdoba y que corresponde al siglo III de la Era $^{25}$ (Fig.4). La obra muestra a la pareja en primer plano, situados ambos personajes de frente al espectador; Polifemo gesticula con su mano izquierda, dirigiendo sus palabras (o sus versos y su canto) a la ninfa, que le escucha atentamente. La iconografía del cíclope responde a los habituales prototipos romanos: es un personaje de anatomía hercúlea, larga y abundante cabellera, tres ojos y fisonomía bastante humanizada, que cubre su cuerpo parcialmente con una piel de animal y se sienta en una roca. Con la mano izquierda empuña un cayado de pastor del que pende una gran siringa. El instrumento tiene nueve tubos, de muy diversa longitud (cuatro largos y cinco cortos), por lo que su morfología presenta un perfil en forma de ala. Por su parte, la nereida aparece sentada a lomos de un Kethos o monstruo de las profundidades, sobre superficie marina, mientras juguetea con su largo cabello, en clara actitud de coquetería ${ }^{26}$. El paisaje que se vislumbra tras las figuras pone en relación este mosaico con el género pictórico de los paisajes bucólicos a los que ya hemos hecho alusión ${ }^{27}$. Pero en este caso, ha llamado nuestra atención su característica silueta, que evoca las ya citadas formaciones rocosas de la llamada "Ribera de los Cíclopes", en la costa siciliana.

25 BLANCO FREIJEIRO, A., "Polifemo y Galatea”, AEA 32, n.99-100 (1959), pp. 174-177. Versión digital en Cervantes Virtual: http://descargas.cervantesvirtual.com/ servlet/SirveObras/12036184306713728432091/019869. pdf?incr=1

${ }^{26}$ Un mosaico de El Djem (Museo Arqueológico de El Djem, Túnez), inspirado probablemente en una pintura, muestra a la pareja en análoga disposición, aunque Polifemo, situado en esta ocasión a la izquierda del campo musivo, tañe una lira con la que agasaja a la nereida (LIMC , "Galateia", n. 25).

27 http://static.panoramio.com/photos/original/188 75308.jpg
En sus Imagines, Filóstrato el Viejo describe un cuadro similar al que comentamos en las líneas precedentes:

"Polifemo está enamorado de Galatea, que juega en el mar mientras él la contempla desde la ladera; y aunque su caramillo está ocioso bajo su brazo, él tiene dispuesta una canción que pondera su blancura, su timidez y su dulzura... la ninfa conduce sobre el mar en calma una cuadriga de delfines bien armonizados. Las hijas de Tritón, servidoras suyas, vigilan a las bestias para que no se desmanden. Sobre la cabeza de Galatea ondea un manto de púrpura marina que da sombra y sirve de vela a su carro" ${ }^{\prime 28}$.

Un relieve marmóreo del antiguo teatro de Nemi (Museo Antico de Nemi, Italia), fechado en el siglo II de nuestra Era, ofrece una iconografía excepcional: los rostros de Polifemo y Galatea (como si de máscaras teatrales se tratara) están representados en posición de tres cuartos y sus miradas convergen en el centro vacío de la composición. El cíclope, identificado por la siringa, tiene una faz muy expresiva en la que destacan sus tres ojos (apenas una incisión señala el de la frente) y unas grandes orejas similares a las de los sátiros. Unas formaciones rocosas pueden vislumbrarse bajo su poblada barba. El rostro de Galatea, situado en el mar, junto a la orilla, es delicado y su tersura contrasta con la plasticidad que posee el modelado del cíclope. Su caracterización como ninfa marina se completa con la imagen de un delfín situado junto a ella ${ }^{29}$.

\footnotetext{
${ }^{28}$ Filóstrato, Imagines, 11, 18.

${ }^{29}$ Roma, Museo Nacional Romano, Palazzo Massimo alle terme: Créditos Ann Raia, 1999. http://www.vroma. org/images/raia_images/polyphemgalatea.jpg.
} 


\section{ICONOGRAFÍA MEDIEVAL Y RENA- CENTISTA.}

Dada su naturaleza, el asunto que nos ocupa no tuvo demasiadas repercusiones iconográficas en los ciclos pictóricos conocidos durante la Edad Media ${ }^{30}$. Sin embargo, las miniaturas que iluminan los textos de Ovidio realizados al finalizar el Medioevo, evocan estos infortunados amores. Como ejemplo de lo que decimos destaca un extraordinario manuscrito conservado en la Biblioteca Real de La Haya ${ }^{31}$, donde el Cíclope, ataviado como un extraño caballero, provisto de armadura, yelmo y escudo, sale de su pétreo antro y se dispone a lanzar una enorme piedra sobre los amantes, a quienes acaba de descubrir. La pareja, ataviada según la usanza de la época, se abraza en primer término, ajena al peligro que se cierne sobre sí (Fig. 5).

Con el Renacimiento, en cambio, los pintores gustaron de recrear con frecuencia el antiguo idilio en sus pinturas, que recobró su actualidad ${ }^{32}$. A partir de este momento, la

30 Entre las fuentes medievales que recrean la historia del Cíclope destacan: Mythographus Vaticanus II, (ed. G. Bode, Cellis 1834), Polifemo; Giovanni di Garlandia, Integumenta Ovidii, De Poliphemo, libro XIII, vv. 464-468; Dante Alighieri, Ecloga IV; Ovide moralisé en prose, Il gigante Polifemo, libro XI, p. 340-341; Berchorius, Ovidius Moralizatus, reductorium morale liber XV; Francesco Petrarca, Trionfi, II. Cf. LIBERTINO, M. "Aci, Galatea e Polifemo". En Iconos, Web de la Cátedra de Iconografía e Iconologia del Dipartimento di Storia delll' Arte Della Facoltà di Scienze Umanistiche della Università di Roma "La Sapienza", en http://www. iconos.it/index.php?id=1166.

31 Biblioteca Real de La Haya 74G 2755 r. http:// www.bu.edu/library/guides/images/polygaldenhaag.jpg.

32 Entre las fuentes renacentistas que evocan la historia que venimos analizando destacan; Angelo Poliziano, Stanze, 115-118; Nicolò degli Agostini, Tutti li libri de Ovidio, p. 150; Lilio Gregorio Giraldi, De Deis gentium varia et multiplex historia qua simul de eorum imaginibus et cognominibus agitur, p. 271,v.57;Natale Conti,Mythologiae, 277. 6. a; Lodovico Dolce, Le Trasformazioni, canto ventesimosesto, p. 279; Vincenzo Cartari, Le Imagini dei Dei degli Antichi, pp. 205-207; p. 224; libro terzo decimo, p. 230; Giovanni Andrea dell'Anguillara, Le Metamorfosi di Ovidio, XIII, p. 230; Gabriele Simeoni, iconografía muestra diversos episodios del mito, aunque siguió siendo Ovidio la fuente literaria más conocida y utilizada por los artistas, por lo que Acis adquiere, en la mayoría de los casos, un papel protagonista. La decoración de la Villa Chigi, conocida como Villa Farnesina, en el Trastévere romano, constituye el punto de partida en toda una serie de ciclos pictóricos que recrean el tema que nos ocupa. En la Farnesina se produjo un verdadero hito con el que los artistas redescubrían los textos de Ovidio (Metamorfosis) y Apuleyo (El asno de oro). A través de dichas pinturas se redescubría la verdadera dimensión de las fábulas de la Antigüedad pagana en la Edad Moderna, en muchos casos utilizadas o reinterpretadas con sentido ejemplarizante. Agostino Chigi, un adinerado banquero sienés, encargó la decoración de esta residencia -imitando las antiguas villas romanas- a los más afamados pintores de la época. Rafael Sanzio fue el encargado de diseñar el conjunto y de la ejecución de algunos de los frescos, aunque en la factura de muchos de ellos participaran también otros $\operatorname{artistas}^{33}$. Las antiguas leyendas, entre ellas los amores de Polifemo y Galatea, recobraban vigor en sus paredes, recreadas con la dignidad y empaque de la pintura antigua.

Entre los frescos de la Farnesina destaca el Triunfo de Galatea, situado en el vestíbulo. Esta pintura es una de las composiciones

La vita et Metamorfoseo d'Ovidio, XIII, pp. 177-178; Gian Paolo Lomazzo, Trattato dell'arte della Pittura, Scoltura e Architettura, in Scritti sulle Arti 1580-1630, cap. XV, Della Forma dell'Oceano, di Nettuno, delle Ninfe e mostri marini, pp. 511-512, Giovanni Bellori, Le Vite dei Pittori, scultori et architetti, Polifemo e Galatea; Lo sdegno di Polifemo. Cf. LIBERTINO, M. "Aci, Galatea e Polifemo", en Iconos, Web de la Cátedra de Iconografía e Iconologia del Dipartimento di Storia delll'Arte Della Facoltà di Scienze Umanistiche della Università di Roma "La Sapienza", en http://www.iconos.it/index.php?id=1167

33 Giulio Romano, Francesco Penni, Raffaellino Colle y Giovanni Baldassarre Peruzzi, Sebastiano del Biombo, Gaspare Dughet, o Sodoma, por citar sólo los más conocidos. 
más alabadas del maestro de Urbino ${ }^{34}$, basada en Teócrito y Ovidio (acaso por influencia de los escritos de Poliziano). Se trata de un conjunto concebido con gran sabiduría, tal vez como horóscopo individual de Agostino Chigi. La composición muestra una verdadera "Apoteosis" de la nereida triunfante, que se acerca a la orilla en una venera, convertida en blanco de las flechas del amor y acompañada por un cortejo fabuloso integrado por tritones, ictiocentauros, delfines y ninfas marinas $^{35}$; desde una de las sobrepuertas, la contempla absorto Polifemo, en una pintura ejecutada por Sebastiano del Piombo ${ }^{36}$. Coronado de pámpanos, como si de un sátiro se tratara, este recio Polifemo viste túnica de color azul brillante y sostiene en sus enormes manos una gran siringa en forma de ala y un cayado de pastor, mientras dirige su mirada al mar, espacio habitado por su amada. La posición serpentinata de la figura sugiere que el cíclope está airado, casi a punto de levantarse, inquieto ante algún acontecimiento inesperado (probablemente la llegada de la nereida a la orilla). En su biografía de Rafael, Vasari señala que Galatea, dirigiendo su mirada a lo alto, es una personificación del Amor Platónico. Por nuestra parte, nos inclinamos a pensar que dirige su mirada, algo desviada, hacia el Cíclope, ya que el conjunto fue ideado como un programa iconográfico con sentido unitario en el que los distintos cuadros se relacionan espacialmente por medio de actitudes y gestos de las figuras en ellos representadas.

La Villa Madama fue la primera de las villas suburbanas concebidas bajo el modelo de las villas romanas de la Antigüedad, que fueron construidas para la celebración

34 KINKEAD, D. T., "An iconographic note on Raphael's Galatea", JWCI, vol. 33 (1970), pp. 313-315. http://www.jstor.org/stable/750904; COLWELL, F.S., "Figures in a Promethean Landscape", Keats-Shelley Journal, vol. 45 (1996), PP. 118-131: http://www.jstor.org/ stable/30210342.

${ }^{35}$ RODRÍGUEZ LÓPEZ, M.I., Mar y Mitología en las culturas mediterráneas, Madrid, 1999, p. 180-182.

\footnotetext{
${ }^{36} \mathrm{http} / / /$ www.lincei.it/img/farnesina/POLIFEMO.jpg
}

de fiestas en el siglo $\mathrm{XVI}^{37}$. Su propósito era rivalizar con las villas de la Antigüedad y con las contemporáneas, como la citada Villa Chigi. Aunque su proyecto nunca fue terminado, su loggia rafaelesca y su jardín colgante hicieron de ella una de las más famosas e imitadas construcciones del Renacimiento. La llamada loggia de Rafael se abre al jardín y como es sabido, en su interior se imita la arquitectura de las construcciones termales de la antigua Roma. El luneto de la zona oriental de la loggia muestra al Polifemo homérico en el interior de su caverna, tendido en el suelo y sumido en el sueño provocado por la embriaguez ${ }^{38}$. Ulises y sus compañeros, en segundo término, urden su ceguera. En esta ocasión, el artista ha destacado los aspectos monstruosos de Polifemo, especialmente su enorme tamaño y su deformidad física. Junto a él se disponen tirados en el suelo un cayado, un ariete y una gran siringa formada por siete anchos tubos unidos entre sí. Como hemos señalado, en la Antigüedad este episodio de la Odisea no daba cabida a la música y sin embargo, los pintores del Renacimiento, conocedores de la vocación musical del cíclope, asociada a su idilio amoroso, la incorporaron a sus composiciones en un claro procedimiento de contaminación iconográfica.

Giulio Romano vuelve a efigiar a Polifemo en uno de los frescos que adornan la Camera di Amore e Psyche del Palazzo Te, en Mantua, la obra maestra de su producción. Como es sabido, esta residencia fue proyectada para Federico II Gonzaga y su realización se llevó a cabo entre 1525 y 1535. Con esta obra, el pintor penetró en los intereses del duque y construyó un palacio concebido como mansión estival de la Corte, lugar de placer ideado para el descanso, considerado como uno de los más importantes

37 LEFEVRE, R., Villa Madama, Editalia. Roma, 1973; NAPOLEONE, C. (ed. ), Villa Madama, Il sogno di Raffaello. Torino, Umberto Allemandi \& C., 2007.

38 http:www.panoramio.com/photos/original/9469 263.jpg 
testimonios del Manierismo en Europa. Entre los mitos que adornan los muros de la estancia dedicada a la unión del amor y el alma (Eros y Psique), no falta la presencia del enamorado Polifemo. Su colosal figura, influida por la maniera miguelangelesca, se identifica por el ojo que adorna su frente, además de una gran siringa de doble hilera de tubos y una clava (análoga a la de Heracles) ${ }^{39}$. El cíclope está a punto de levantarse; tiene el cuerpo ya girado, en ese serpentinato contrapposto característico de aquel tiempo, y su gesto parece airado ya que acaba de sorprender, el devaneo entre Acis y Galatea. La cuidadosa elaboración del instrumento musical, de compleja factura, subraya la importancia de la música como atributo distintivo del personaje. Es una siringa de múltiples tubos, y sus dos hileras sugieren una sonoridad polifónica, no exenta de cierta complejidad en su ejecución (Fig. 6).

Otro de los manieristas que se ocupó del tema que estudiamos, fue el pintor boloñés Pelegrino Tibaldi (1527-1596), cuya estancia romana a mediados del siglo XVI (1547-1549) le puso en contacto con el arte de Miguel Ángel, cuya maniera habría de influir notablemente en sus creaciones. Tibaldi pintó, entre 1554 y 1556, algunas de las estancias del palacio del Cardenal Poggio, en Bolonia, entre cuyos frescos destacan algunas escenas de la Odisea, enmarcadas por arquitecturas fingidas de carácter ilusionista. En tales cuadros se desarrolla un programa iconográfico muy ambicioso que recrea la imagen de un Polifemo brutal y ebrio, en el momento de ser cegado por Ulises; las aficiones musicales del hijo de Posidón se sospechan, en primer plano, por la presencia de una enorme siringa de múltiples cañas, acomodada en el sue-

\footnotetext{
${ }^{39}$ En algunas ocasiones se le ha llamado PolifemoHeracles. En nuestra opinión, dicha clava es una evolución del cayado de pastor que Polifemo ostentaba en la Antigüedad y que adquiere enormes dimensiones para adecuarse al tamaño de su poseedor. El citado mosaico del Alcázar de los Reyes Cristianos de Córdoba muestra un atributo semejante (Vide supra)
}

lo junto al cayado del Cíclope ${ }^{40}$. Dicha aptitud musical no es traba, en esta ocasión, para que el pintor subrayara, asimismo, las tendencias antropófagas de Polifemo, mediante los huesos humanos que se encuentran a su lado como restos de su festín. Esa brutalidad del monstruo caníbal queda latente, asimismo, en la escena en la que se dispone, feroz y violento, a lanzar una piedra contra el infortunado Acis ${ }^{41}$.

Proyectado por Antonio de Sangallo el Joven y terminado por Miguel Ángel, el Palazzo Farnese de Roma, constituye uno de los mejores logros del Renacimiento tardío. Los frescos de la Galería (una estancia de 20 metros de longitud por seis metros de anchura), destinada a contener la colección de esculturas antiguas de la familia Farnesio, fueron realizados entre 1596 y 1601 por el boloñés Anibale Carracci y por su hermano Agostino. La decoración de este ambiente fue comisionada por el cardenal Odoardo Farnese y su programa iconográfico celebra la omnipotencia del Amor, una idea muy extendida en el Renacimiento. Dicha temática suscitó un gran escándalo por tratarse de la residencia privada de un cardenal, particularmente cuando el severísimo pontífice Clemente VIII, estaba al frente de la Iglesia. Aníbal Carracci abandonó los trabajos en 1605 por desavenencias con el cardenal, y también por motivos de salud; los frescos serían finalizados por sus discípulos (Domenichino, Sisto Baldocchio y su nieto Antonio Carracci). Fue entonces cuando el tema del ciclo pictórico cambió de manera radical, para convertirse en una metáfora moralizante del triunfo de la virtud sobre el vicio y canto de alabanza a las glorias y empresas de la familia Farnese.

\footnotetext{
40 http://www.flickr.com/photos/16472880@N06/35 15093855/sizes/o/

41 CALÍ, M., SANCHO, J. L., ALONSO, A., De Miguel Ángel a El Escorial: momentos del debate religioso en el arte del siglo XVI, Coll. Arte y Estética, vol. 32, Madrid, Akal, 1994, n. 61.
} 
Dicho programa está constituido por escenas que representan los amores de los dioses; en él, Polifemo aparece dos veces, ocupando los compartimentos cuadrangulares situados en el centro de los lunetos de los lados menores la estancia. En uno de ellos, el cíclope, sentado en una roca y junto a un gran cayado curvo ( una evocación del antiguo pedum) se dispone a tañer su siringa para conquistar el corazón de la nereida, quien en compañía de otras dos ninfas marinas parece completamente ajena a los requerimientos amorosos de éste. La pared frontera muestra la vertiente más brutal de Polifemo, que acaba de sorprender el requiebro entre Acis y Galatea y se dispone a arrojar contra ellos una piedra de gran tamaño. Todavía lleva consigo la siringa (de nueve cañas), colgada a su espalda mediante una cinta de cuero. El furor hace presa en su figura y su cuerpo se contorsiona en un violento giro, mientras los amantes, en el margen derecho de la composición, tratan de huir en vano. En ambos casos, el gigante luce pieles animales como parte de su atuendo, que cubren sólo parcialmente su extraordinario y gigantesco cuerpo. Su cabello es fuerte y encrespado y su gesto expresa vehemente patetismo (Fig. 7).

Las sucesivas ediciones de las Metamorfosis de Ovidio que vieron la luz desde el siglo XVI, ilustradas con bellos grabados, debieron contribuir, significativamente, a la circulación y difusión del tema que tratamos. Algunos de las estampas impresas en tales ediciones serían, además, el modelo compositivo adoptado, de forma convencional, por los pintores.

\section{ICONOGRAFÍA EN EL ARTE BARROCO}

Tanto éxito gozó el tema de los amores de Galatea y Polifemo y que a las obras de la literatura antigua vinieron a sumarse otras fuentes literarias de las que destaca muy especialmente la Fábula de Polifemo y Galatea, un gran poema del culterano español
Luis de Góngora y Argote, que vio la luz en 1612. Mediante la estrofa octava real, el poeta cordobés interpretó de forma original, a la usanza barroca, el texto de Ovidio. Es sabido que con esta obra nacía el estilo culterano, lleno de simetrías, transposiciones, metáforas de metáforas, hipérbaton, perífrasis, giros latinos, cultismos, alusiones y elusiones de términos, procurando sugerir más que nombrar y dilatando la forma, de manera que el significado se desvanezca a medida que va siendo descifrado. Y ello debió de ser, sin duda, acicate para que el asunto siguiera siendo uno de los temas preferidos por los escritores ${ }^{42} \mathrm{y}$ artistas plásticos, especialmente en las decoraciones de los frescos barrocos. El grabado del frontispicio de una de las ediciones del poema culterano, firmado J. de Courbes $^{43} \mathrm{f}$ (ecit), es una recreación satírica, casi grotesca, de uno de los frescos de Anibal Carracci en la Galería Farnese, ya comentados en líneas precedentes.

Durante el siglo XVII, los pintoresdecoradores de frescos mantuvieron vigente la tradición icónica iniciada en el siglo anterior. Así, por ejemplo, en 1614, Sisto Baldochio se encargaba de decorar algunos salones del Palazzo Verospi, en Roma. En uno de los ambientes de la planta noble se muestra

\footnotetext{
42 SOLER MERENCIANO, A., "Presencia ovidiana en el auto-sacramental: El Polifemo de Juan Pérez de Montalbán (1633)", Cuadernos de Filología Clásica, Estudios latinos, 1998, n.15, pp. 573-583; CRUZ CASADO, A., "Secuelas de la Fábula de Polifemo y Galatea: versiones barrocas a lo burlesco y a lo divino", Criticón 49, 1990, pp.51-59. ALONSO, D. "El Polifemo, poema barroco", Atenea [on line]. 2009, n.500, pp. 231-249.

43 Jean COURBES (París, 1592-1641). Grabador francés activo en España entre 1620 y 1640, principalmente en Madrid, aunque trabajó también para clientes de otras partes del país. Grabó numerosos retratos, incluyendo el de Lope de Vega para cuyos trabajos produjo muchas ilustraciones. También retrató a Góngora, el rey Felipe IV y a nueve miembros de la familia Hurtado de Mendoza para la Historia de Cuenca (Madrid, 1629). Es el autor de numerosos frontispicios con retratos y láminas para libros, entre los que destacan sus alegorías, ejecutadas en colaboración con Melchor Prieto (muerto en 1648) para su Psalmodia Eucharistica (Madrid, 1622).

Cf. http://www.answers.com/Library/Art/Enciclope dia-cid-14982661
} 
la naturaleza más tranquila de Polifemo quien, sentado en una roca, a la orilla del mar, hace música para Galatea, que ocupa su medio natural, junto a otros seres marinos. Como es habitual, los atributos del cíclope son el cayado, y la siringa, además, en esta ocasión, de un zurrón propio de los pastores.

Entre las obras que a principios del Seiscientos recrearon el tema que nos ocupa, destaca la decoración al fresco del Palazzo Lancelotti ai Coronari, obra ejecutada por Agostino Tassi (1566-1644) para el cardenal Orazio Lancellotti ${ }^{44}$. En la Sala de los Palafreneros, sobre las puertas que dan paso a los apartamentos, Agostino Tassi realizó cuatro paisajes en los que se narra la historia de Polifemo, Acis y Galatea, según el relato de Ovidio. En el primer recuadro, colocado en la sobrepuerta del lado oeste, Polifemo está sentado sobre una roca, a la orilla del mar, mientras observa a Galatea. Bajo el pie derecho del Cíclope, la siringa yace silenciosa, a la espera de que Polifemo comience a componer canciones en honor de la nereida. Esta, en el mar, está acomodada sobre una venera y su manto flotante hace las veces de vela a su embarcación. En la lejanía se ve una pareja formada por un tritón y una nereida.

En el segundo recuadro, el que corresponde al lado meridional, Polifemo también está sentado sobre la roca, al pie de un árbol, mientras tañe una canción para Galatea, que juega en el mar con un tritón. En el tercer recuadro (lado norte) el cíclope está de pie, con la siringa entre las manos, mientras da la espalda a Galatea, que lo observa desde la orilla del mar, sentada en su venera; junto a ella, otra nereida y un tritón se abrazan, mientras en el cielo se han representado dos erotes arqueros. En este cuadro, el instrumento musical ha adquirido una naturaleza inusitada, tanto por su tamaño como por su forma. Es un aerófono de diez tubos de desigual tamaño, que por

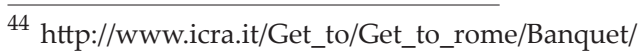
Palazzo_Lancellotti.htm
}

su morfología y por la manera en la que Polifemo lo sostiene (casi de forma vertical), más se asemeja a un órgano portativo que a una siringa propiamente dicha.

El último cuadro, colocado en la sobrepuerta del flanco oriental, muestra a un Polifemo que acaba de descubrir a Galatea con su amante y está a punto de lanzar una enorme piedra a su rival. Está de pie, con la roca entre las manos, cerca de la orilla del mar, mientras Galatea y Acis huyen aterrorizados. Un detalle que merece subrayarse en la composición de estos frescos, que fingen ser cuadros enmarcados, son las colgaduras rojas, que simulan un telón teatral abierto, como si las escenas de la historia estuvieran desarrollándose en un escenario. El pintor juega con el espacio real y el espacio fingido y con lo que el profesor Gállego denominó en su día como "el cuadro dentro del cuadro" (Fig. 8) ${ }^{45}$.

Tanta importancia adquirió el cíclope como músico en el Barroco, que hasta los instrumentos musicales de esta época se sirvieron de su desdichada historia como tema de decoración, es decir como medio expresivo para aludir a la música misma. Tras larga andadura iconográfica, Polifemo se había convertido en un personaje asociado a la música. El extraordinario clave de la colección Crosby Brown, en el Museo Metropolitano de Nueva York, refrenda esta hipóte$\operatorname{sis}^{46}$. Los laterales de la caja del instrumento están dorados y trabajados con finos relieves

\footnotetext{
${ }^{45}$ Los frescos de Giovanni Lanfranco (Roma, Galería Doria Panphili, 1620) y Giovanni Francesco Romanelli (Roma Galería Pallavicini, 1653) continúan explotando esta tradición temática, sacando a primer plano al cíclope músico que canta y toca melodías para su amada.

46 RIPIN, E. M.“The Couchet Harpsichord in the Crosby Brown Collection" Metropolitan Museum Journal, Vol. 2,(1969), pp.169-178;JSTOR,Stable URL:http:// www.jstor.org/stable/1512590. POLLENS, S., "Michele Todini's Golden Harpsichord: An Examination of the Machine of Galatea and Polyphemus." Metropolitan Museum Journal, Vol. 25 (1990). POWERS, W., "The Golden Harpsichord of Michele Todini (1616-1690)", Heilbrunn Timeline of Art History. New York: The Metropolitan Museum of Art, 2000
} 
en los que se representa un gran cortejo de seres marinos; las patas del instrumento han sido suplantadas por figuras de tres tritones de extremidad bífida, que hacen la función de tenantes, entre los cuales se sitúa una pareja de seres marinos (un tritón y una tritonisa). Todas estas figuras, de madera dorada, apoyan sobre un gran tablero que repite la forma de ala del instrumento y que apoya en el suelo sobre diez garras de león. Completando el conjunto, a ambos lados del instrumento propiamente dicho, se disponen las figuras exentas del cíclope y de Galatea, sentados sobre pedestales rocosos. La nereida hace un gesto declamatorio con sus manos, mientras el apuesto músico (cuyo único signo ciclópeo es el ojo inciso sobre su frente) toca la gaita para ella ${ }^{47}$.

Muchos pintores, entre ellos los franceses Poussin, Lorena, Perrier, de la Fosse y otros tantos plasmaron el mito en sus lienzos, al tiempo que los pintores decoradores italianos continuaban haciéndose eco del mismo en sus frescos. Poussin aborda el tema de Polifemo como músico enamorado en varias ocasiones, destacando las versiones del mismo que se conservan hoy en el Museo del Louvre y en el Museo del Ermitage. La primera de ellas, ambientada en un atardecer de dorados destellos, muestra en primer plano el abrazo de Acis y Galatea, rodeados por un cortejo de amorinos, dos de los cuales tratan de ocultar a los amantes ante los ojos de Polifemo. El cíclope, sentado en lo alto de un risco, toca la siringa, mientras varias parejas de nereidas y tritones, de amorosa actitud, se asoman a la orilla. En la versión conservada en San Petersburgo el pintor ha representado la soledad de Polifemo, otorgando gran importancia al paisaje, verdadero protagonista del conjunto. Sobre la frondosa campiña se disponen pequeñas figuritas entre las que destacan, en primer plano, varias ninfas de las fuentes (identificadas por sus coronas vegetales y los cántaros que simbolizan sus aguas),

47 http://www.metmuseum.org/toah/images/h2/h2 -89.4.2929.jpg sátiros entretenidos en su carnal contemplación y otros grupos de personajes situados en los planos intermedios. En el centro de la composición, al fondo de esta, coronando una alta cumbre que casi roza las nubes, está Polifemo, sentado de espaldas al espectador, tocando un aerófono de largo tubo. El cíclope, de carnación pétrea, se funde con la roca donde habita, mirando al mar donde vive su amada y acallando su melancolía a través de la música.

En uno de sus célebres paisajes con figuras, Claudio de Lorena evocó también el tema que nos ocupa, situando a los jóvenes amantes en primer plano, acompañados por erotes y al solitario Polifemo observando el idilio desde la lejanía, sentado en lo alto de una roca. Los rayos solares que atraviesan las nubes iluminan el mar, una superficie de aspecto nacarado, como evocación del propio nombre de la ninfa marina.

A mediados del siglo XVII, Francois Perrier recreó en sus pinceles un gran cortejo marino, de naturaleza festiva, que celebraba los amores de la nereida con Acis. Galatea, sentada en un carro tirado por delfines, se acerca a la orilla en compañía de su joven enamorado, que sostiene uno de los extremos de su manto flotante (París, Museo del Louvre) ${ }^{48}$. La pareja va precedida por tritones, nereidas y otros seres del mar, mientras un amor con la antorcha ardiente en sus manos sobrevuela el intenso azul celeste. El gigantesco Polifemo contempla la escena desde una roca. Recostado y con una siringa en la mano, gesticula en ademán doloroso; tras él, en el fondo de la composición, se advierte la imagen de un volcán que ruge y cuyo fuego tiñe de gris el cielo, acaso como presagio del desdichado final que esperaba a los amantes.

Un pequeño cobre del pintor francés Charles de la Fosse, hoy en el Museo del Prado, muestra también a la pareja de amantes

\footnotetext{
48 http://cartelen.louvre.fr/cartelen/visite?srv=obj_ view_obj\&objet=cartel_4749_5935_p0005915.001.jpg_ obj.html\&flag=true
} 
recostados en primer término, ensimismados en su ensueño amoroso, mientras desde lo alto, fundido con el paisaje montañoso, les observa el agraviado Polifemo, como un "voyeur", actitud característica de otros salvajes, los sátiros ${ }^{49}$.

Los pintores galantes representaron con frecuencia en sus obras tanto el Triunfo de Galatea, asunto que les brindaba una ocasión de exhibir alegres y ampulosos cortejos marinos, como el abrazo de ésta con el joven Acis. Entre los pintores italianos, destacan los Triunfos de Galatea de Sebastiano Ricci (Londres, Royal Academy of Arts) ${ }^{50}$ y Corrado Giaquinto (Milwaukee Art Museum) $)^{51}$, cuyas composiciones se distinguen por el movimiento y la riqueza cromática; por lo general muestran a la nereida en su elemento, montada sobre una venera tirada por delfines o hipocampos, con el manto flotando al viento y rodeada de un bullicioso tropel de seres marinos y erotes. Desde la orilla, sentado en las rocas, la observa en silencio Polifemo. Galatea simboliza, desde el siglo XVI, la fertilidad del mar, su belleza y sus incontables dones $^{52}$ y no cabe duda de que los cortejos marinos que celebran su "Triunfo" debieron de resultar muy apropiados y gratos para la decoración de estancias magnificentes.

Concepción análoga adquiere el tema en los pinceles del francés Van Loo (San Petersburgo, Museo del Ermitage),

\footnotetext{
${ }^{49}$ Vide infra.

${ }^{50} \mathrm{http}: / /$ www.maicar.com/GML/000Images/dim/di vinities8120.jpg

${ }^{51}$ http://1h4.ggpht.com/_OhG8z0vKCZo/ Rm8wLMiEWPI/AAAAAAAABcM/awKovJStj8Y/ IMGP5017.jpg

52 Galatea pasó a representar en el Renacimiento, la personificación del mar, sus aspectos gratificantes y la expresión icónica de su fertilidad y de sus riquezas. Giorgio Vasari utilizó su imagen como alegoría del agua en la decoración de la Sala de los Elementos del Palazzo Vecchio de Florencia. Cf. RODRÍGUEZ LÓPEZ, M.I., "Posidón y el thíasos marino en el arte mediterráneo (desde sus orígenes hasta el siglo XVI)", Madrid, 1993, Capítulo IV, p. 754
}

quien representó a Polifemo en actitud de tocar la siringa para acompañar la llegada de la nereida. La presencia de siete pequeños amorcillos, en actitudes diversas, insinúa la pasión de Polifemo, que tañe para su adorada ninfa. El movimiento del agua y de las nubes se percibe a través de los contrastes cromáticos, producidos por la erupción del volcán rugiente situado tras el cíclope, cuyas cenizas oscurecen el cielo ${ }^{53}$.

\section{ROMANTICISMO Y SIMBOLISMO}

Desde mediados del siglo XVIII y durante toda la centuria siguiente, el episodio preferido por los artistas es el idilio íntimo de Galatea y Acis, que son víctimas del airado Cíclope, observados o atacados por él. Buen ejemplo de ello es el cuadro de Johann Heinrich Tischbein el Viejo (Galería de Arte de Dresde) $)^{54}$, de 1758, que presenta a Polifemo como un verdadero "mirón", ensimismado contemplando las caricias de los amantes situados en primer término ${ }^{55}$. Por su parte, Alexandre Charles Guillemot, en una interpretación academicista de 1827 (Colección privada), situó a Polifemo muy alejado, como si su imagen fuera la propia cima de la montaña que habita, inmerso en su elemento, con su siringa en la mano y mirando hacia el mar donde espera poder divisar a Galatea. En primer plano se representa el arrullo de los amantes, ajenos, en este caso, a su fatal destino ${ }^{56}$.

Otros pintores, como Jean Antoine Gros (1771-1835) o François Edouard Zier

\footnotetext{
$\overline{53 \text { http://cgfa.acropolisinc.com/1/jloo1.jpg }}$

54 http://www.1st-art-gallery.com/thumbnail/18966 6/1/Acis-And-Galatea,-1758.jpg

55 Este carácter de voayeurs de los sátiros es una característica inherente a su naturaleza desde la Antigüedad. En no pocas ocasiones, estos salvajes fueron representados en actitud de contemplar el idilio o la consumación del amor entre diversas parejas, como por ejemplo la unión de Posidón y Amímone.

56 http://images.artnet.com/WebServices/picture.as px?date $=19940215 \&$ catalog=JAMES-7836\&gallery $=1108$ $89 \&$ lot $=00008 \&$ filetype $=2$
} 
(1856-1924) destacan el temor de los amantes ante la presencia de Polifemo, escondidos en una cueva ${ }^{57}$. La iconografía de la citada obra de Gros (Chrysler Art Museum) es muy interesante, ya que el Cíclope, enfurecido, no toca su característica siringa, sino que mientras corre por el campo, presa de los celos, hace sonar una estrepitosa trompa, cuyo aterrador sonido llega a los amantes y hace que Galatea se tape los oídos, justificando la expresión temerosa de su rostro.

En 1866, el escultor francés Auguste Louise Ottin (1811-1890) fue comisionado para realizar las esculturas de la llamada Fuente Medici en los jardines del Palacio de Luxemburgo, en París, trasladada entonces de su emplazamiento original con motivo de las reformas urbanas del Barón Haussman ${ }^{58}$. Ottin se encontró con un conjunto escenográfico, una fachada en la que se abre la fuente en forma de gruta, imitando los ninfeos de la antigua Roma ${ }^{59}$. En ella, encontramos otra interesante recreación del texto de Ovidio. Ottin disponía de una fachada arquitectónica con decoración naturalista en la que se insertan dos hornacinas laterales y el pilón central. En las hornacinas se alojan las estatuas de Pan y Diana, mientras que como tema central se representa el momento en que Acis y Galatea, en una gruta, son sorprendidos por el gigantesco cíclope, que observa sus caricias, desde arriba, en una posición inestable. La narración ovidiana adquiere vida en el mármol y el bronce de las esculturas de Ottin gracias al contraste entre las texturas y la combinación de materiales, tan grata al gusto neo-barroco, así

\footnotetext{
57 Desde la Antigüedad, las cuevas y grutas son recintos en los que se consuma el amor, por estar alejadas de la vista. Cf. BUXTON, R. El imaginario griego. Contextos de la Mitología griega, Cambridge, 2000, p. 101 y ss.

58 El traslado tuvo lugar en 1861, momento en que Alphonse de Gisors restauró el conjunto y creó un gran estanque y el pilón donde se situarían las esculturas de Ottin. Cf. VV.AA., Paris et ses fontaines, de la Renaissance à nos jours, Paris, 2006.

59 Las grutas y su reproducción en arquitectura fueron muy populares en Italia desde el Renacimiento, imitando a las grutas de la antigua Roma.
}

como por la multiplicidad de puntos de vista de las figuras. El abandono y la languidez de los amantes se contrapone a la fuerza de Polifemo, figura dotada de una extraordinaria energía plástica. Todos y cada uno de los detalles del conjunto subrayan la desproporción y diferencias entre los amantes y su rival. La siringa es, como en otros casos, atributo de Acis, figura cuya posición recostada parece sugerir de antemano su ulterior naturaleza de personificación fluvial (Fig. 9).

En los últimos años del siglo XIX el tema que abordamos siguió siendo un asunto bastante popular entre los artistas; Gustave Moreau (1826-1898) evocó al cíclope en varias ocasiones (1880 y 1896, las más conocidas de ellas). Precursor del movimiento simbolista, el pintor francés gustó, como es bien sabido, de representar lo monstruoso y también mujeres fascinantes y perversas (Salomé, Deyanira, Dalila y otras), por lo que el asunto que tratamos fue de su interés ya que contenía los ingredientes más distintivos de su imaginario pictórico. Su Galatea de 1880 (Musée d'Orsay, París) parece una evocación onírica, ya que su blanca figura se destaca en una selva sobrenatural de corales ${ }^{60}$ y pequeñas flores en la que resplandece su dorada y larguísima cabellera. Polifemo es apenas una gran máscara triste, un ser melancólico, que emerge en el paisaje y contempla a la mujer inasible con respeto casi religioso. Como han señalado algunos autores, Moreau propone una interpretación original, personal, moderna y mágica del antiguo mito, centrando su interés en la esencia de éste, la oposición entre dos contrarios:

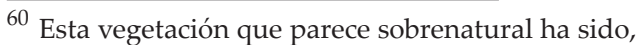
no obstante, el objeto de minuciosos estudios por parte del artista, realizados a partir de un libro de botánica marina conservado en el Museo de historia natural, donde Moreau se había matriculado como oyente, en 1879. El trabajo de la pintura al óleo, en la que se mezclan frotados y raspados, otorga un aspecto precioso a la obra, como si se tratase de esmalte. El Salón de 1880 es el último al que participó Moreau, por lo que Galatea determina su triunfo y el apogeo de su carrera.

Cf.http://www.musee-orsay.fr/index.php?id $=851 \& \mathrm{~L}=3 \& \mathrm{tx} \_$commentaire_pi $1 \% 5 \mathrm{BshowUid} \% 5 \mathrm{D}$ $=357 \&$ no_cache $=1$
} 
belleza y monstruosidad, que llenan el cuadro de luces y sombras (Fig. 10).

En otra versión del asunto, fechada en 1896, el artista ha enfatizado aún más la fantasía y el exotismo de la pintura. La ninfa marina está desconsolada, casi inerme, y su piel es ahora tan blanca como la de un espectro; yace recostada sobre el lecho de un río (su amado Acis transformado) mientras un Polifemo, con aspecto de estatua oriental, la observa mudo y doliente. Un paisaje onírico de brillantes colores envuelve a las figuras que han sido desprovistas de toda sensualidad para pasar a ser sólo imágenes simbólicas.

En dicho universo simbolista destaca también el magnífico Cíclope de Odilon Redon (1840-1916), un trabajo de 1900 (Kröller-Müller Museum, Otterlo, Holanda) acaso inspirado por la obra de Moreau. Polifemo es un ser monstruoso, con un enorme ojo que ocupa el centro de su rostro; su gigantesco busto emerge tras las rocas, desde donde contempla a Galatea, tendida sobre el cristalino río que una vez fuera su amado (Fig. 11). Algunos autores han señalado la influencia del arte japonés en Redon, muy notable en este cuadro que pudo evocar una impresión de Utagawa Kuniyoshi (1797- 1861) titulada Umibōzu, especialmente en el manejo de la composición asimétrica y en el tratamiento de la perspectiva ${ }^{61}$. Pero dejando a un lado toda posible fuente de inspiración, el pintor simbolista se muestra lírico, puro, dominador de la técnica y como se le ha llamado el "Príncipe de los sueños" ${ }^{2}$.

Ponemos punto final a esta trayectoria iconográfica con el Polifemo de Maurice Denis (1870-1943), artista que evocó los amores de Polifemo en su etapa juvenil (1907, Museo Pushkin, Moscú), representando

${ }^{61}$ El ultramundo extremo-oriental en la pintura de Odilon Redon, EuskadiAsia http://www.euskadiasia. com/ESTUDIOS_ORIENTALES/DOCUMENTOS/_ultramundo_odilon_redon.

62 Gibson, M. Odilon Redon (1840-1916): El príncipe de los sueños, Köln. Ed. Taschen, 1998. al cíclope como un solitario en la playa. El pintor, ha interpretado el mito griego en clave cotidiana, ofreciendo los atributos esenciales para su lectura e interpretación, pero de forma un tanto ambigua. Unos jóvenes descansan y se divierten en la orilla del mar, mientras un hombre corpulento sentado en una roca, de espaldas a ellos y ajeno a su diversión, toca el aulós mientras observa a la muchacha (o la nereida), de actitud coqueta $^{63}$, que se baña en el mar. La música es, una vez más, su arma para embelesar a la amada y el mejor consuelo ante su desamor.

\section{MEDITACIÓN FINAL}

$\mathrm{Al}$ igual que sus hermanas las nereidas, Galatea personifica el mar en calma y la belleza misma del piélago; por su parte, el Cíclope, con su único ojo, es la personificación de la poderosa y activa fuerza del volcán, el Etna, cuyo cráter (acaso el único ojo de Polifemo) se asoma para contemplar las cristalinas y blancas aguas del Mediterráneo. Y el viento (la música de la siringa) une con su rumor a los elementos opuestos. Polifemo es pues el volcán, que puede estar "dormido", es decir enamorado y tratando de conquistar a la blanca ninfa, o activo y violento, lanzando lava y piedras al mar (las piedras que arroja contra su rival). Acis, el río que desemboca en el mar, es un obstáculo para Polifemo, que no duda en aplastarlo.

La música de Polifemo forma parte de la Naturaleza misma. Es el viento que silba o susurra, viento que canta enamorado; $Y$ es también el furioso volcán que ruge y contra cuyos riscos choca el mar. Polifemo es un pastor, un ser inmerso en la naturaleza, y su figura y su historia tienen mucho que ver con el sentimiento profundo con que los griegos percibieron la naturaleza que los circundaba. Por eso, salvo contadas excepciones donde le vemos con una lira u otro instrumento

$\overline{63}$ Esta actitud de coquetería se percibe en que la figura parece estar acicalando sus cabellos. 
musical, la siringa (un instrumento asociado al ámbito natural, pastoril y dionisíaco) constituye uno de los atributos iconográficos más característicos asociados a su imagen.

Como hemos podido comprobar, el bestial antropófago se transforma, se humaniza y deja de comer carne humana (se civiliza) para convertirse en un poeta enamorado. Como narra Ovidio, para agradar a Galatea "dejó su cueva y su ganado; se peinó la pelambrera roja y rufa; se bañó; se cortó la barba; y dejó de atacar a las naves" (Metamorfosis XIII). Aunque Ovidio y Góngora se refieran a su horrenda y ronca voz, el poder de la música le sirvió al Cíclope de consuelo

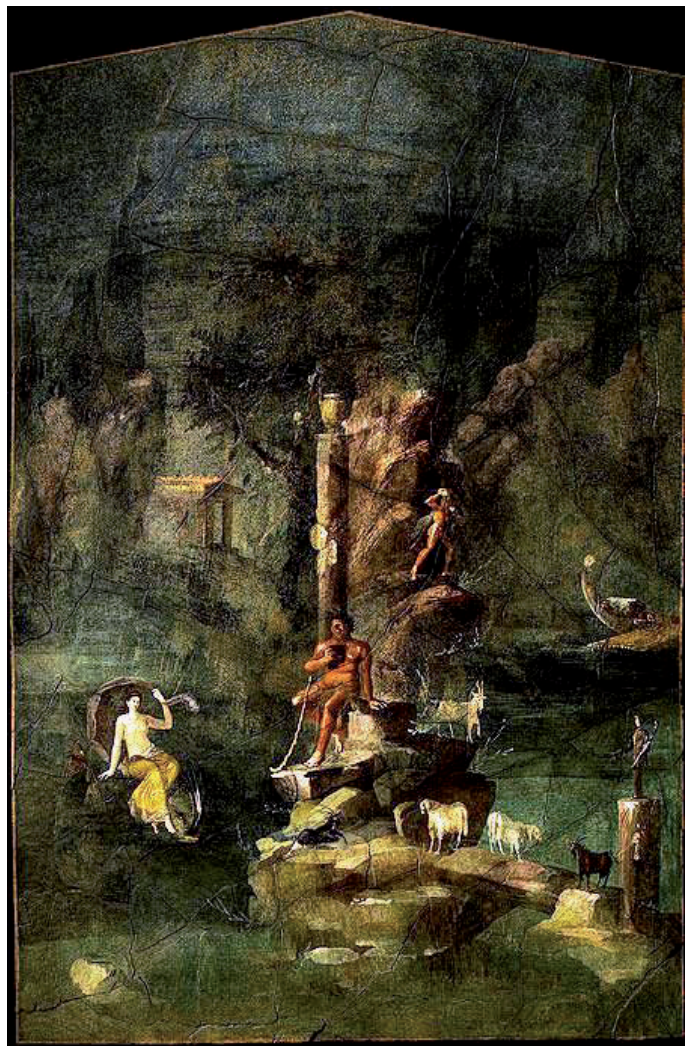

- Fig.1. Polifemo y Galatea. Fresco procedente de la Villa de Boscotrecase. S. I d.C. Nueva York, Metropolitan Museum of Art.

Foto: http://www.metmuseum.org/toah/worksof-art/20.192.17 en su delirio amoroso, y ésta pasó a ser una de las facetas más características de su personalidad. Andando el tiempo, el mito homérico quedó relegado a segundo plano en la imaginación de los artistas, al tiempo que ganaba terreno la narración bucólica de Teócrito y la historia de amor y celos, con tres protagonistas, forjada por Ovidio.

Parafraseando a Alexander A. Parker, concluimos nuestra disertación con una idea: El juego de contrarios luz-oscuridad o bellezafealdad simboliza, en el mito de Polifemo, las pulsaciones vitales de las fuerzas de la naturaleza ${ }^{64}$.

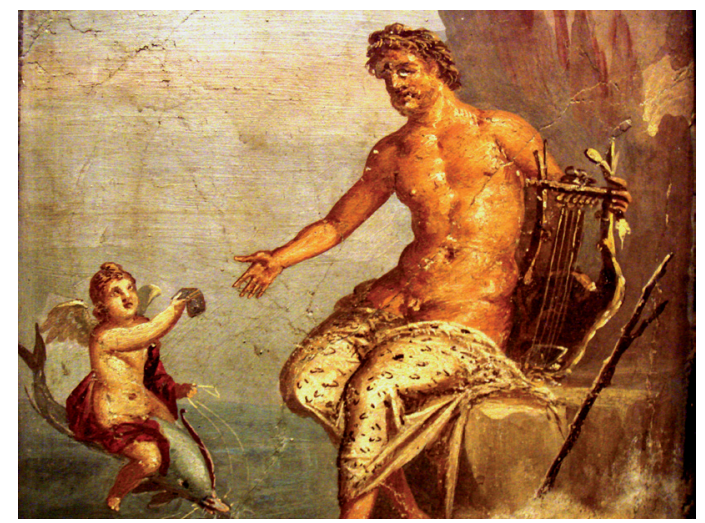

- Fig.2. Polifemo recibiendo una carta de Galatea. Fresco procedente de la Casa del Naviglio, en Pompeya. S. I d.C. Nápoles, Museo Arqueológico Nacional.

Foto:http://upload.wikimedia.org/wikipedia/ commons/7/7e/Affreschi_romani_-_polifemo_ galatea_-_pompei.JPG

\footnotetext{
${ }^{64}$ GÓNGORA, L., Fábula de Polifemo y Galatea (edición a cargo de Alexander A. Parker), Madrid, Cátedra, 1990.
} 


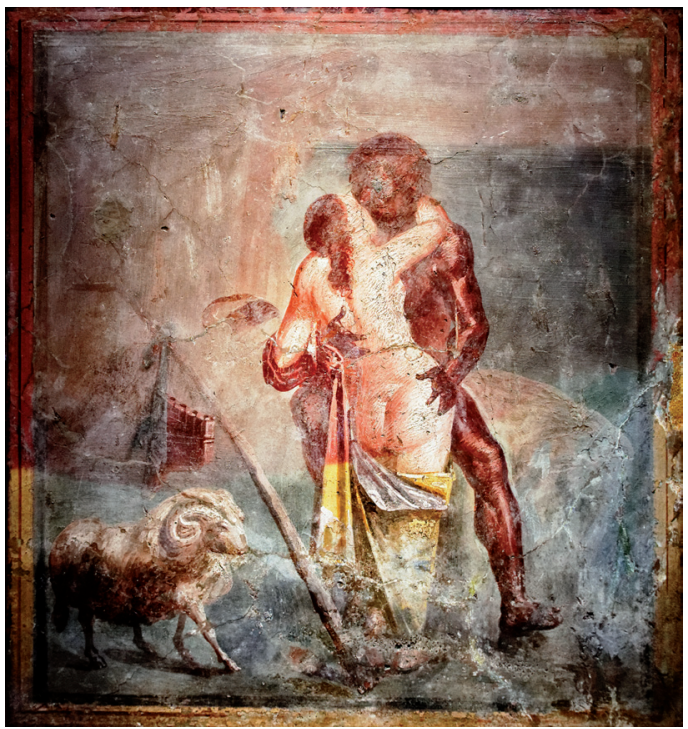

- Fig.3. Polifemo y Galatea. Fresco de la Casa della Caccia Antica. S. I d.C. Pompeya.

Foto:http://upload.wikimedia.org/wikipedia/ commons/6/63/Polyphemus_and_Galatea_ Pompeii_MAN_Napoli_Inv27687.jpg

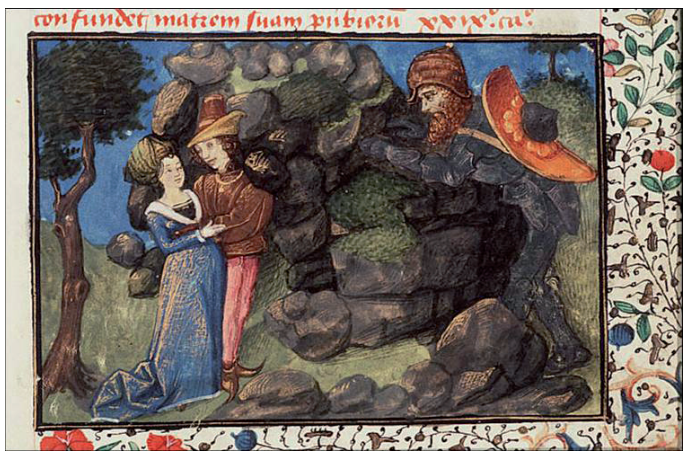

- Fig.5. Miniatura de un Ovidio moralizado que representa a Polifemo, Acis y Galatea. Biblioteca Koninlijke, La Haya 74G 2755 r.

Foto:http://www.bu.edu/library/guides/images /polygaldenhaag.jpg

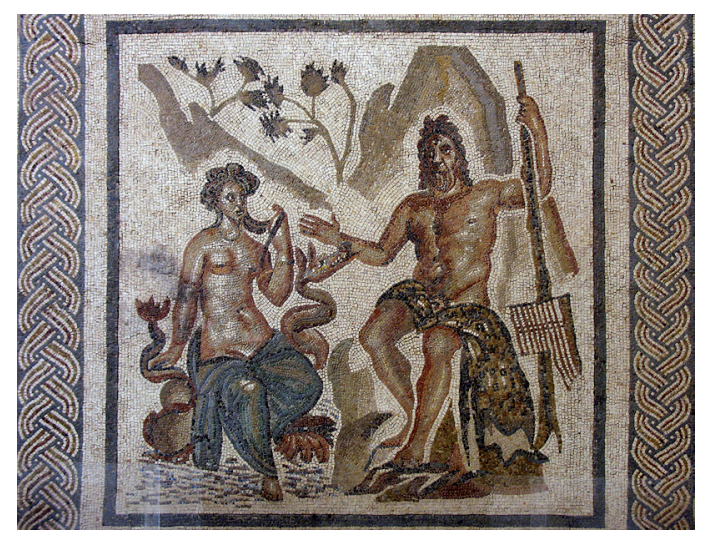

- Fig.4. Polifemo y Galatea. Mosaico procedente de la antigua Corduba. S. III d.C. Córdoba, Alcázar de los Reyes Cristianos. Foto de la autora.

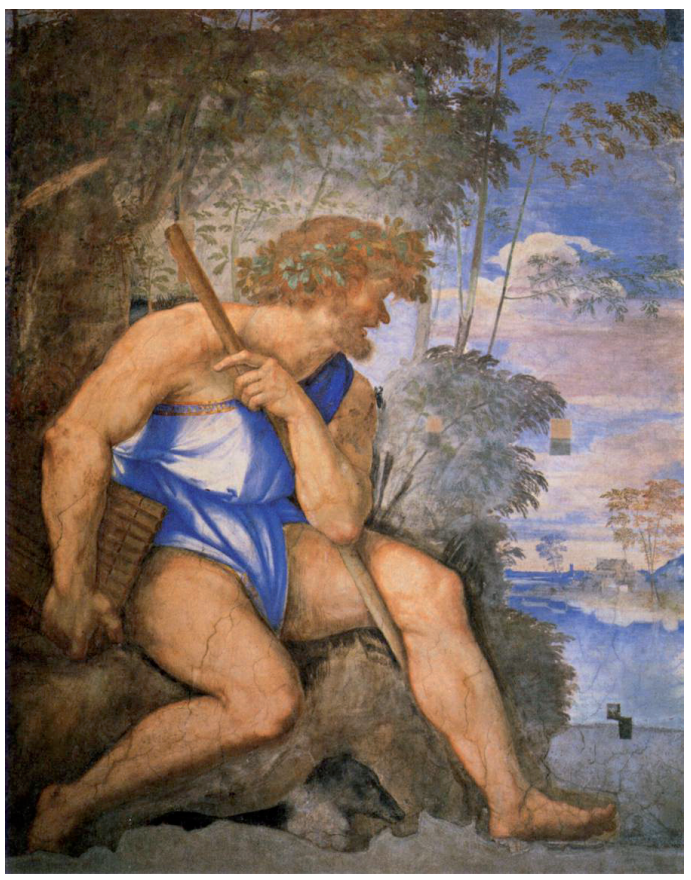

- Fig.6. Sebastiano del Piombo. Fresco de la Villa Farnesina, en Roma. Polifemo.

Foto:http://upload.wikimedia.org/wikipedia/ commons/5/5d/Sebastiano_del_piombo\%2C_ polifemo.jpg 


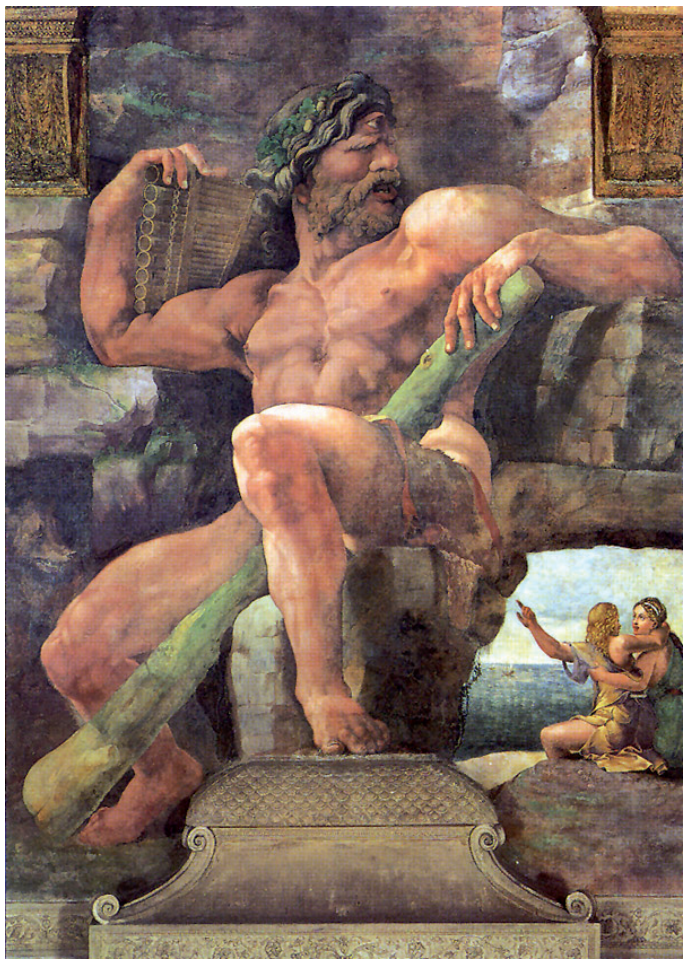

- Fig.7. Polifemo celoso por Acis. Giulio Romano, Sala de Amor y Psique del Palazzo Te, Mantua. 1526-1528.

Foto:http://images3.wikia.nocookie.net/__ cb20120613183949/mythology/images/a/a9/Po lyphemus.jpg

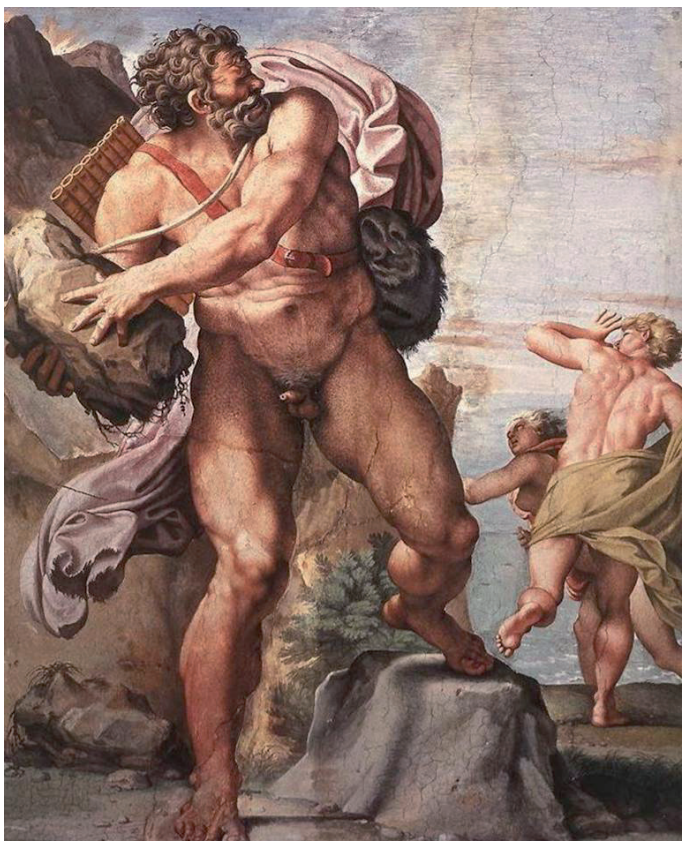

- Fig.8. Anibal Carracci. Frescos de la Galería del Palacio Farnese. 1596-1601. Roma.

Foto:http://upload.wikimedia.org/wikipedia/ commons/5/59/Annibale_Carracci_-_The_Cyclops_Polyphemus_-_WGA04461.jpg

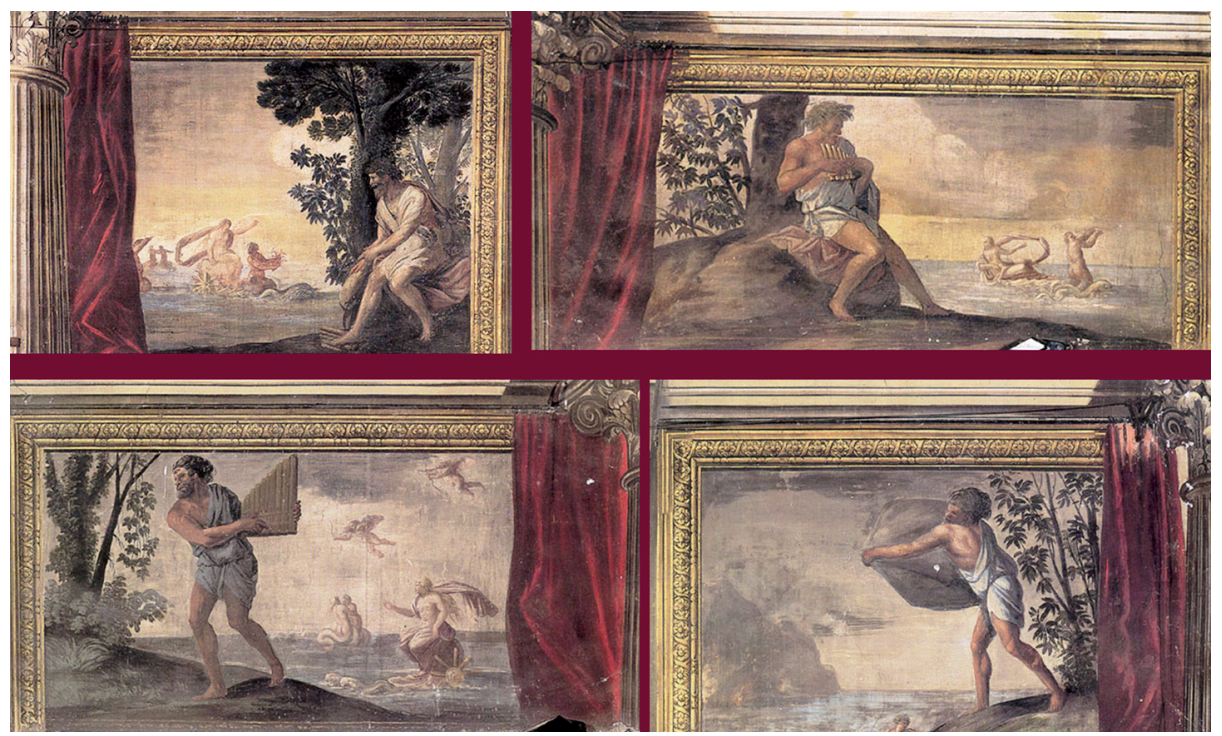

- Fig.9. Agostino Tassi. Primera mitad del siglo XVII. Sobrepuertas de la Sala de los Palafreneros en el Palacio Lancelotti.

Fotocomposición de la autora basada en las fotos de: http://www.icra.it/Get_to/Get_ to_rome/Banquet/Palazzo_Lancellotti.htm 


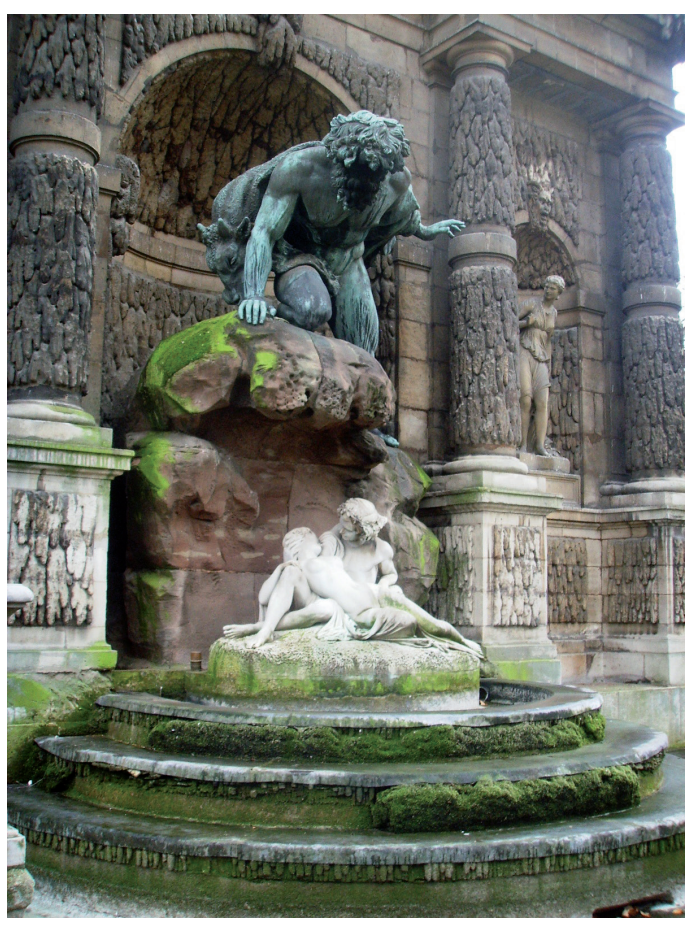

- Fig.10. Fuente Medici. Ottin. Polifemo, Acis y Galatea. 1806. Jardines del Palacio de Luxemburgo, París.

Foto:http://upload.wikimedia.org/wikipedia/ commons/0/0d/Palazzo_del_luxembourg_ fontana_di_maria_de\%27_medici_05.JPG

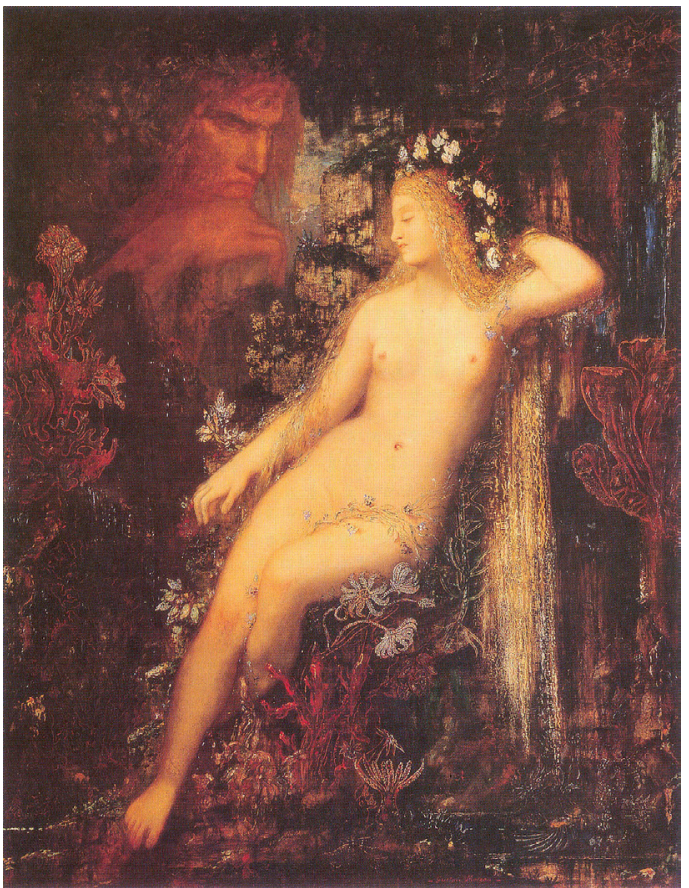

- Fig.11. Gustave Moreau, Galatea. 1880. París, Musee d'Orsay.

Foto: http://upload.wikimedia.org/wikipedia/ commons/2/2a/Moreau-Galatea.jpg

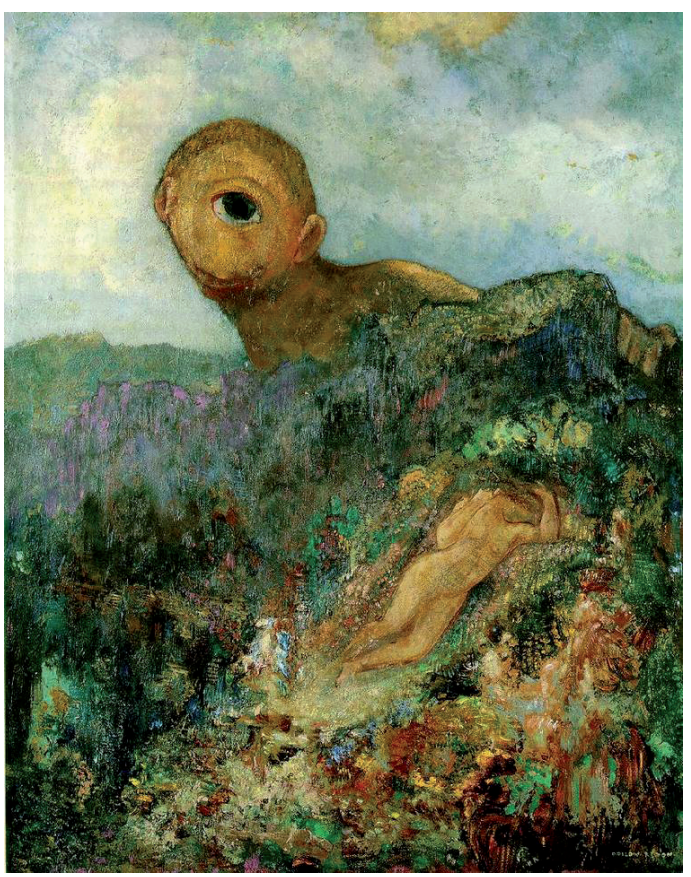

- Fig.12. Odilon Redon, Cíclope. 1900. Otterlo, Kröller-Müller Museum.

Foto: http://suite101.net/article/odilon-redon-el -ciclope-a48270\#axzz2LjJINOQ7 